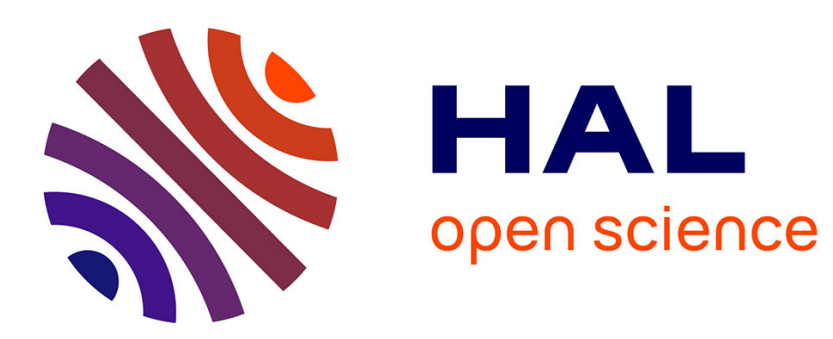

\title{
Oxidation State, Local Structure, and Ab-Initio XAFS Modeling of Chromium in Contaminated Soils and Model Compounds
}

\author{
M. Peterson, G. Brown, G. Parks
}

\section{- To cite this version:}

M. Peterson, G. Brown, G. Parks. Oxidation State, Local Structure, and Ab-Initio XAFS Modeling of Chromium in Contaminated Soils and Model Compounds. Journal de Physique IV Proceedings, 1997, 7 (C2), pp.C2-781-C2-783. 10.1051/jp4:1997235 • jpa-00255314

HAL Id: jpa-00255314

https://hal.science/jpa-00255314

Submitted on 1 Jan 1997

HAL is a multi-disciplinary open access archive for the deposit and dissemination of scientific research documents, whether they are published or not. The documents may come from teaching and research institutions in France or abroad, or from public or private research centers.
L'archive ouverte pluridisciplinaire $\mathbf{H A L}$, est destinée au dépôt et à la diffusion de documents scientifiques de niveau recherche, publiés ou non, émanant des établissements d'enseignement et de recherche français ou étrangers, des laboratoires publics ou privés. 


\title{
Oxidation State, Local Structure, and Ab-Initio XAFS Modeling of Chromium in Contaminated Soils and Model Compounds
}

\author{
M.L. Peterson, G.E. Brown Jr. and G.A. Parks \\ Department of Geological \& Environmental Sciences, Stanford University, Stanford, California 94305-2115, U.S.A.
}

\begin{abstract}
We have used XAFS spectroscopy, combined with the ab-initio multiple scattering code FEFF 7 , to model the structures of $\mathrm{Cr}$ compounds and $\mathrm{Cr}$ sorption complexes and precipitated phases on soils impacted by industrial $\mathrm{Cr}$ effluent. We have had success in ab-initio modeling of the near-edge structure of $\mathrm{Cr}$ model compounds, accurately simulating the $\mathrm{Cr}$ pre-edge and edge fine structure which are due to bound-state transitions and multiple scattering among the absorber $\mathrm{Cr}$ and its nearest shell of oxygen atoms. We have calibrated the pre-edge feature, a $1 s$ to $3 d$ electronic transition, and applied this to determining $\mathrm{Cr}$ (VI)/Cr(III) ratios in natural, $\mathrm{Cr}$-contaminated soils. The pre-edge feature is particularly useful in following the electron transfer reaction between $\mathrm{Cr}(\mathrm{VI})$ and $\mathrm{Fe}(\mathrm{II})$ on oxide surfaces such as $\mathrm{Fe}_{3} \mathrm{O}_{4}$ (magnetite) which, as we have seen in both lab and field studies, results in the reduction of $\mathrm{Cr}$ (VI) to $\mathrm{Cr}$ (III).
\end{abstract}

\section{INTRODUCTION}

$\mathrm{Cr}$ in the environment is most hazardous to human health when present in its hexavalent form. $\mathrm{Cr}(\mathrm{VI})$ is highly mobile in groundwaters and is known to be carcinogenic. Trivalent $\mathrm{Cr}$, in contrast, is quite insoluble and tends to precipitate from aqueous solution as a solid oxyhydroxide phase, limiting its bioavailability. Electron sources for $\mathrm{Cr}$ (VI)-to-Cr(III) reduction in Cr-contaminated soils include Fe(II)-bearing mineral phases which may be naturally present in soils. One such mineral is magnetite $\left(\mathrm{Fe}^{2+} \mathrm{Fe}_{2}^{3+} \mathrm{O}_{4}\right)$, which undergoes a topotactic oxidation to maghemite $\left(\gamma-\mathrm{Fe}_{2}^{3+} \mathrm{O}_{3}\right)$ upon exposure to oxidants such as aqueous $\mathrm{Cr}(\mathrm{VI})$.

This study presents results of the molecular-level sorption mode and oxidation state of $\mathrm{Cr}$ at the magnetite surface as determined by X-ray absorption fine structure (XAFS) spectroscopy, as well as evidence of magnetite-to-maghemite conversion as seen by transmission electron microscopy (TEM). Initial results of long-term oxidation/reduction experiments suggest that a thin layer of maghemite passivates magnetite, and slows the $\mathrm{Cr}(\mathrm{VI})$ reduction rate considerably in only a few hours.

XAFS fitting results have demonstrated that partial to full reduction of $\mathrm{Cr}(\mathrm{VI})$ to $\mathrm{Cr}(\mathrm{III})$ may occur in situ at the magnetite surface, whereas mixed $\mathrm{Cr}(\mathrm{III} / \mathrm{VI})$ oxidation states are stable at most silicate mineral surfaces because these mineral phases lack potential electron sources for $\mathrm{Cr}(\mathrm{VT})$ reduction. Theoretical modeling of the $\mathrm{Cr}$ K-edge X-ray Absorption Near-Edge Structure (XANES) of model compounds has been used to simulate experimental XANES. Results from such analyses are useful for determining which single- and multiple-scattering paths interact to define the XANES, and are valuable for local structure and oxidation state determinations.

\section{EXPERIMENTAL METHODS}

Cr K-edge XAFS data were collected at the Stanford Synchrotron Radiation Laboratory (SSRL) on beamlines 4-2 and 4-3 using a $\operatorname{Si}(220) \phi=0$ double crystal monochromator. On beamline $4-2$, harmonics were eliminated by detuning the $X$-ray beam by $60 \%$. On beamline 4-3, a Pt-coated mirror was used for harmonics rejection, with the $\mathrm{X}$-ray beam used at full flux. $\mathrm{Cr}$ contaminated soil samples were separated into magnetic and nonmagnetic mineral fractions, ground, and contained in Teflon sample holders with Kaptan tape windows. Soils were mounted at $45^{\circ}$ to the synchrotron X-ray source, and fluorescent X-rays were collected with a Stern-Heald ion chamber detector [1]. $\mathrm{Cr}$ model compounds were mixed with BN to provide approximately one absorption length at $6 \mathrm{keV}$ and pressed into Al sample holders with Kaptan tape windows. Their XAFS spectra were measured in transmission using $\mathrm{N}_{2}$-filled ion chamber detectors. All spectra were normalized in energy to the edge position $(5989.0 \mathrm{eV})$ of a metallic $\mathrm{Cr}$ foil $(16 \% \mathrm{Cr}$ in austen steel). Data analysis of XAFS spectra was performed using EXAFSPAK [2], and theoretical modeling of XAFS spectra was accomplished using FEFF 7 [3]. Electron microbe data were collected on a Jeol Superprobe 733. High resolution TEM data were collected with a Philips CM20FEG.

\section{RESULTS AND DISCUSSION}

Building on previous observations of $\mathrm{Cr}(\mathrm{VI})$ reduction or partial reduction occurring in the presence of magnetite $[4,5]$, we have calibrated the $\mathrm{Cr}$ XAFS pre-edge peak height to quantify $\mathrm{Cr}(\mathrm{VI}) /$ total $\mathrm{Cr}$ in environmental samples and model compounds. $\mathrm{Cr}$ K-edge XANES spectra may be well fit using a sum of pseudo-Voigt peak shapes plus a step function (Fig. 1). Several of the peak amplitudes change progressively as a function of $\mathrm{Cr}(\mathrm{VD}) / \mathrm{total} \mathrm{Cr}$ (Fig. 2). The peak with the most marked peak size change is the pre-edge peak, which is attributed to $1 s$ to $3 d$ bound state transition. The height of the pre-edge peak was 
calibrated using model compound mixtures, with an accuracy of $\pm 3 \%$ [6], and the calibration was used to determine $\mathrm{Cr}(\mathrm{VI}) /$ total $\mathrm{Cr}$ contents of samples with $\mathrm{Cr}$ present in unknown oxidation states.
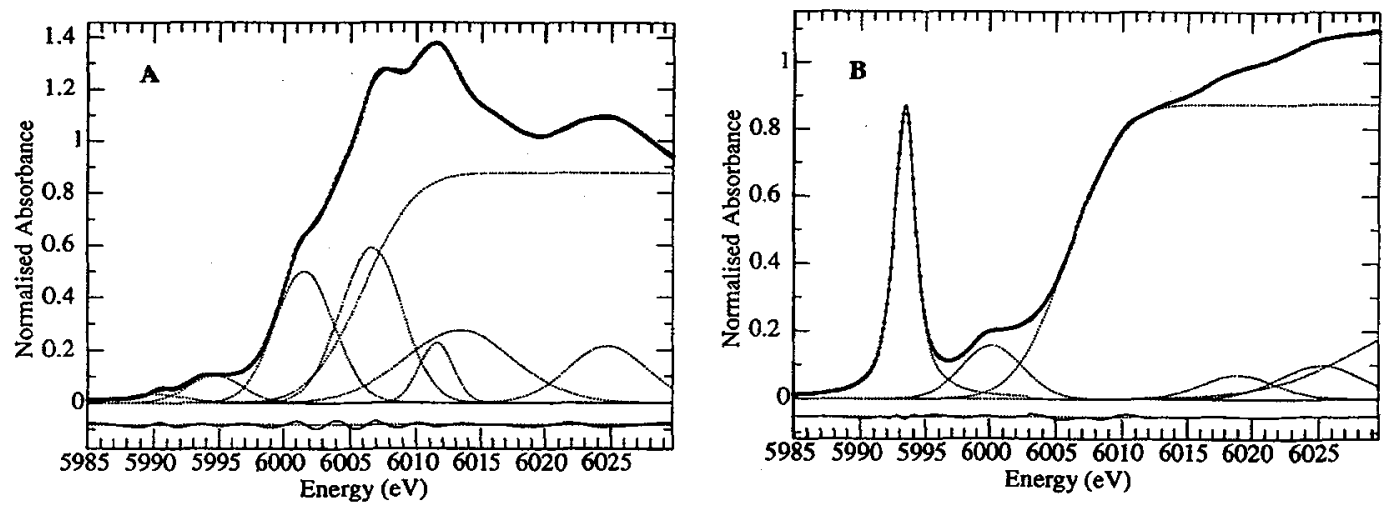

Figure 1: $\mathrm{Cr}$ K-edge XANES data and peak deconvolution for $\mathrm{Cr}(\mathrm{III})$ and $\mathrm{Cr}(\mathrm{VI})$ model compounds (A) $\mathrm{Cr}_{2} \mathrm{O}_{3}$ and $(\mathrm{B}) \mathrm{Na}_{2} \mathrm{CrO}_{4} \cdot 4 \mathrm{H}_{2} \mathrm{O}$. An edge step function was fit to the $\mathrm{Cr}(\mathrm{VI})$ edge and held constant in fitting mixtures of $\mathrm{Cr}(\mathrm{III})$ and $\mathrm{Cr}$ (VI) model compounds.

Cr-contaminated soils from two field sites were examined: (1) a chemical waste disposal facility at Sandia National Laboratory, Albuquerque, NM; and (2) a chromium plating facility near Keyport, WA which had experienced Cr effluent seepage into the surrounding soil from a corroded disposal pipe. The $\mathrm{Cr}$ contents at Sandia were as high as 2 wt.\%, with highly variable $\mathrm{Cr}(\mathrm{VI}) /$ total $\mathrm{Cr}$ contents: 2 to $67 \%$ of the $\mathrm{Cr}$ was present as $\mathrm{Cr}(\mathrm{VI})$ in the Sandia soils. Trace quantities of Fe(II)bearing minerals were present, but no difference in $\mathrm{Cr}$ oxidation state was noted on the $\mathrm{Fe}$ (II)-rich mineral fraction. In contrast, soils from the Keyport site showed no measurable $\mathrm{Cr}$ (VI) on the Fe(II)-rich mineral fraction (predominantly magnetite). All the Cr present associated with magnetite was present as $\mathrm{Cr}$ (III) whereas the $\mathrm{Cr}$ associated with the silicate mineral fraction contained up to $6.4 \% \mathrm{Cr}(\mathrm{VI}) /$ total $\mathrm{Cr}$. Total $\mathrm{Cr}$ contents of this soil were much lower, $\leq 0.1 \mathrm{wt} . \%$, which may have allowed the electron transfer from $\mathrm{Fe}^{2+}$ in magnetite to occur without significant passivation of the magnetite surface.

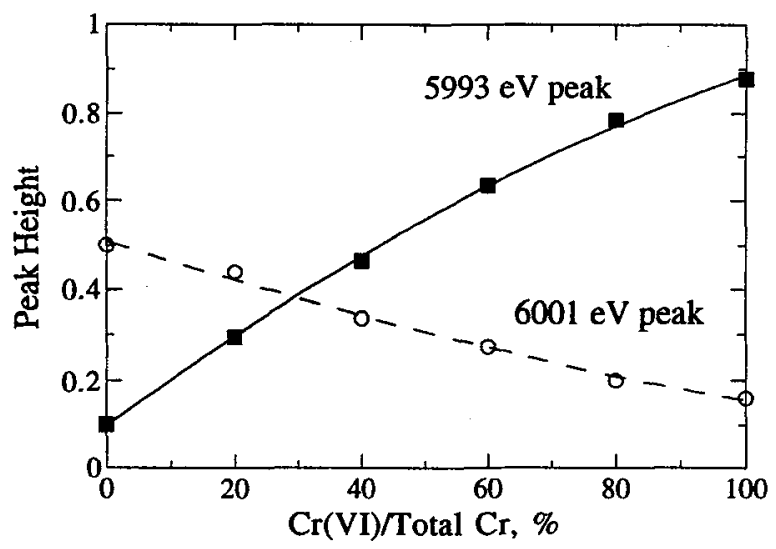

Figure 2: Trends in peak height with $\mathrm{Cr}(\mathrm{VI}) /$ total $\mathrm{Cr}$ content for the $\mathrm{Cr}$ model compounds of Fig. 1. The model-calibrated pre-edge peak height was used to determine $\mathrm{Cr}(\mathrm{VI}) /$ total $\mathrm{Cr}$ content of natural soil samples.

FEFF fits of the Sandia and Keyport soils were used to determine that the local structures about $\mathrm{Cr}$ in these soils are consistent with several $\mathrm{Cr}$ (III) and $\mathrm{Cr}(\mathrm{VI})$ phases, including $\mathrm{CrOOH}, \mathrm{Cr}_{2} \mathrm{O}_{3}, \mathrm{CrPbO}_{4}$, and $\mathrm{CaCrO}_{4}$. The presence of these phases in the soils was confirmed by electron microprobe analysis. Ab-initio FEFF 7 models of the XANES of Cr(III) and $\mathrm{Cr}$ (VI) compounds provide a quantitative understanding of the main contributions to the $\mathrm{Cr}$ K-edge structure. For $\mathrm{Cr}$ (VI), $\mathrm{Cr}$-O single-and multiple-scattering in the $\mathrm{CrO}_{4}$ tetrahedra alone simulates the XANES spectra quite well, and our results are similar to theoretical modeling of $\mathrm{CrO}_{4}^{2-}$ done by others [7, 8]. In contrast, FEFF models of $\mathrm{Cr}$ (III) compounds require singlemultiple-scattering paths out to $>5 \AA$ from the central Cr to closely simulate the XANES. 
Passivation of the magnetite surface by maghemite was investigated through long-term $\mathrm{Cr}(\mathrm{VI})$ reduction experiments using synthetic magnetite in anoxic $50 \mathrm{mM} \mathrm{Cr}(\mathrm{VI})$ solution at $\mathrm{pH} 7$. The heterogeneous oxidation/reduction proceeds by a reaction such as

$$
3 \mathrm{Fe}^{2+} \mathrm{Fe}_{2}^{3+} \mathrm{O}_{4}+2 \mathrm{H}^{+}+\mathrm{Cr}^{6+} \mathrm{O}_{4}^{2-}=4.5 \gamma-\mathrm{Fe}_{2}^{3+} \mathrm{O}_{3}+0.5 \mathrm{H}_{2} \mathrm{O}+\mathrm{Cr}^{3+} \mathrm{OOH}
$$

or

$$
3 \mathrm{Fe}^{2+} \mathrm{Fe}_{2}^{3+} \mathrm{O}_{4}+2 \mathrm{H}^{+}+\mathrm{Cr}^{6+} \mathrm{O}_{4}^{2-}=3 \gamma-\mathrm{Fe}_{2}^{3+} \mathrm{O}_{3}+\mathrm{H}_{2} \mathrm{O}+2 \gamma-\mathrm{Fe}_{2-\mathrm{n}}^{3+} \mathrm{Cr}_{\mathrm{n}}^{3+} \mathrm{O}_{3} \text {. }
$$

The exact stoichiometry of the reaction depends on the final $\mathrm{Cr}$ phase which forms, as well as the degree to which the initial magnetite converts to maghemite. TEM evidence (Fig. 3a) reveals an alteration rim on magnetite grains which had been reacted at pH 7 in anoxic $\mathrm{Cr}$ (VI) solution for 5 weeks. In contrast, magnetite which had not been exposed to $\mathrm{Cr}$ (VI) shows no such surface alteration (Fig. 3b).
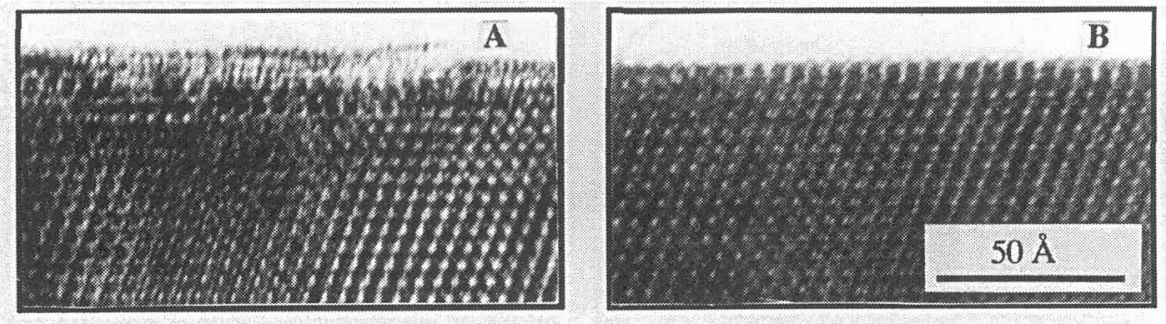

Figure 3: A synthetic magnetite grain oriented along the $<110>$ zone axis shows (A) development of an altered surface region after reaction with $50 \mathrm{mM} \mathrm{Cr}(\mathrm{VI})$ solution, whereas an unreacted magnetite grain in the same orientation (B) shows bulk structure out to the edge. Scale is the same for both photos.

\section{CONCLUSIONS}

Mitigation of chromium contamination in the environment requires knowledge of the Cr oxidation state(s) and phase(s) present. XAFS spectroscopy on natural soils can be used to quantify $\mathrm{Cr}(\mathrm{VI}) /$ total $\mathrm{Cr}$ and to identify the $\mathrm{Cr}$-bearing mineral and precipitate phases associated with soil minerals. XANES analysis of mineral separates demonstrated that $\mathrm{Cr}$ (VI) may be reduced to $\mathrm{Cr}(\mathrm{III})$ by naturally occurring magnetite, whereas $\mathrm{Cr}$ (VI) is not reduced on non $\mathrm{Fe}$ (II)-bearing minerals. XAFS spectroscopy, in conjunction with TEM and other techniques, has been used to describe the surface structure and oxidation states of the sorbed or precipitated $\mathrm{Cr}$ contaminant and to show the surface alteration of the magnetite substrate. Theoretical modeling of $\mathrm{Cr}$ XANES indicates that single- and multiple-scattering among $\mathrm{Cr}(\mathrm{VI})$ and its first shell of oxygens dominates in the $\mathrm{Cr}(\mathrm{VI})$ XANES, whereas the Cr(III) XANES contains contributions from many more shells of atoms $>5 \AA$ distant from the central Cr.

\section{Acknowledgments}

We acknowledge Professor Carol Stein, University of Washington, Seattle, WA, USA for providing the soil samples, the Stanford Center for Materials Research for TEM and electron microprobe facilities, the staff of the Stanford Synchrotron Radiation Laboratory for their support, and the National Science Foundation (grant EAR-9406490) for funding this research. SSRL is funded by the Department of Energy and the National Institutes of Health.

\section{References}

[1] Lytle F.W., Greegor R.B., Sandstrom D.R., Marques E.C., Wong J., Spiro C.L., Huffman G.P., and Huggins F.E. Nucl. Instrum. Method s 226 (1984) 542-548.

[2] George G. and Pickering I., EXAFSPAK: A suite of computer programs for analysis of X-ray absorption spectra. Stanford Synchrotron Radiation Laboratory report.

[3] Zabinsky S.I., Rehr J.J., Ankudinov A., Albers R.C., and Eller M.J. Phys. Rev. B 52 (1995) 2995-3009.

[4] White A.F. and Peterson M.L. Geochim. Cosmochim. Acta 60 (1996) 3799-3814.

[5] Peterson M.L., Brown G.E., Jr., and Parks G.A., Colloids Surfaces A 107 (1996) 77-88.

[6] Peterson M.L., Brown G.E., Jr., and Parks G.A., In Voigt, J.A., Bunker, B.C., Casey, W.H., Wood, T.E., and Crossey, L.J., Eds., Aqueous Chemistry and Geochemistry of Oxides, Oxyhydroxides, and Related Materials: Materials Research Society, Pittsburgh, in press.

[7] Kutzler F.W., Natoli C.R., Misemer D.K., Doniach S., and Hodgson K.O. J. Chem. Phys. 73 (1980) $3274-3288$.

[8] Bianconi A., Garcia J., Benfatto M., Marcelli A., Natoli C.R., and Ruiz-Lopez M.F. Phys. Rev. B 43 (1991) 68856892. 